九州大学学術情報リポジトリ

Kyushu University Institutional Repository

Synthesis of 2', 3'-Cyclic Ribonucleotide Derivative from Ribonucleoside with Phosphorylating Agent, MTB0, and its Application to Synthesis of Oligonucleotide

I io, Masayoshi

Food Chemistry Institute, Faculty of Agriculture, Kyushu University

Kobayashi, Yukuharu

Eto, Masayoshi

Food Chemistry Institute, Faculty of Agriculture, Kyushu University

Yano, Ken-ichi

他

https://doi.org/10.5109/22870

出版情報: 九州大学大学院農学研究院紀要. 19 (2/3)，pp.73-81，1975-03. Kyushu University バージョン：

権利関係 : 


\title{
Synthesis of $2^{\prime}, 3^{\prime}$-Cyclic Ribonucleotide Derivative from Ribonucleoside with Phosphorylating Agent, MTBO, and its Application to Synthesis of Oligonucleotide
}

\author{
Masayoshi Iio, Yukuharu Kobayashi*, Masayoshi Eto, \\ Ken-ichi Yano, Hirohisa Omura and Morifusa Eto ${ }^{\dagger}$
}

\author{
Food Chemistry Institute and Laboratory of Pesticide Chemistry,t \\ Faculty of Agriculture, Kyushu University, Fukuoka
}

(Received September 9, 1974)

\begin{abstract}
Present paper deals with the reaction of 2-methylthio-4H-1,3,2-benzodioxaphosphorin-2oxide (MTBO) with the 5'-0-protected ribonucleoside and its application to a specific synthesis of an oligonucleotide. The significance of the method is also discussed. MTBO reacted with $5^{\prime}$-0-monomethoxytrityluridine to give the corresponding $2^{\prime}, 3^{\prime}$ cyclic phosphate in a good yield $(80 \%)$. The cyclic phosphate was treated with pancreatic ribonuclease A yielding 5'-0-monomethoxytrityluridine 3'-phosphate quantitatively. The resulting $2^{\prime}$-hydroxy group was benzoylated with benzoic anhydride. With the nucleotide thus obtained in combination with $\mathrm{N}, 2^{\prime}, 3^{\prime}$-O-tri-benzoyluridine and $2^{\prime}$, 5'-0-diacetyluridine $3^{\prime}$-phosphate, a trinucleotide uridylyluridylyluridine (UpUpU) was synthesized using dicyclohexylcarbodiimide as condensing agent followed by removal of protective groups and DEAE-cellulose column chromatography.
\end{abstract}

\section{INTRODUCTION}

In the previous papers we reported that MTBO (I) can phosphorylate hydroxy groups of aliphatic alcohols and ribonucleosides to give alkyl S-methyl phosphorothiolates. The phosphorothiolates thus obtained can be converted into mono-or dialkyl phosphate by iodine oxidation or isoamylnitrite treatment in aqueous or alcoholic media as shown in Fig. 1. (Iio et al., 1973). As one of the applications using MTBO method, we could synthesize adenosine $3^{\prime}, 5^{\prime}$-cyclic phosphate from adenosine via adenosine $5^{\prime}$-S-methyl phosphorothiolate (Fig. 2) (Eto et al., 1974). When 5'-O-protected ribonucleosides were subjected to react with MTBO, cis-diol

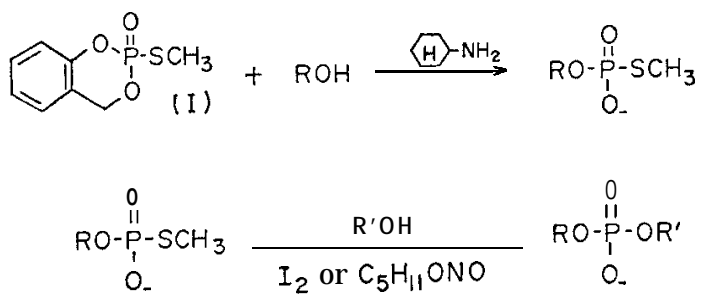

Fig. 1. Reaction of MTBO with alcohol.

\footnotetext{
* Present Adress : Kohjin Co. Oita.
} 


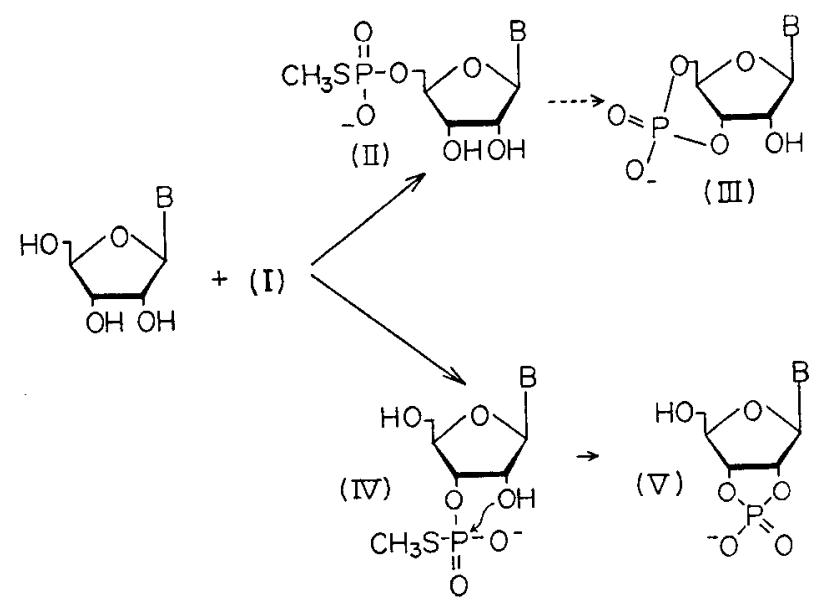

Fig. 2 Reaction of MTBO with ribonucleoside.

system of the nucleosides showed an interesting behavior to the phosphorylating agent and ribonucleoside $2^{\prime}, 3^{\prime}$-cyclic phosphates were major products, rather than phosphorothiolate.

Ribonucleoside $2^{\prime}, 3^{\prime}$-cyclic phosphates are important starting material in the synthesis of oligo- or polyribonucleotides, since they can be quantitatively converted into ribonucleoside $3^{\prime}$-phosphates by enzymatic ring opening. The resulting phoshpates can form internucleotidic bond with $5^{\prime}$-hydroxy group of another ribonucleotide by the help of such condensing agents as dicyclohexylcarbodiimide and aromatic sulfonyl chlorides.

Incidently our laboratory have also reported that phosphodiester bonds of nucleic acid chain are split by a number of antitumor agents, which seems to be one of the main causes of the antitumor potency of the agents (Murakami and Yamafuji, 1970; Yamafuji et al., 1970 ; Yamafuji et al., 1971). Studying the mechanism is a matter of interest both from organochemical and from pharmacological stands of view. In order to elucidate the mechanism of the breakage of polynucleotide chains by the antitumor agents, sequentially known oligonucleotides are requisite to a model experiment where intermediates or products would be characterized and isolated. Such oligonuoleotides can be obtained only by chemical synthesis on fairly large scale.

We attempted the synthesis of a trinucleotide, uridylyl $\left(3^{\prime}-5^{\prime}\right)$ uridylyl $\left(3^{\prime}-\right.$ $\left.5^{\prime}\right)$ uridine (UpUpU), where MTBO method can be appropriately employed to obtain an intermediate compound, 5'-O-monomethoxytrityluridine $3^{\prime}$-phosphate from its nucleosidic material. In the MTBO reaction, the latter was converted into its cyclic phosphate, which was then hydrolyzed into the desired product by ribonuclease A treatment.

Starting from the MTBO reaction product and other material, UpUpU was chemically obtained in a pure state using dicyclohexylcarbodiimide as a condensing agent. 


\section{MATERIALS AND METHODS}

General procedure

Nucleosides and nucleotides (Kohjin) were dried at $100^{\circ} \mathrm{C}$ for $5 \mathrm{hr}$ in vacuo before use. Pancreatic ribonuclease A was purchased from Sigma Chemical Co. Reagent grade pyridine was dried over calcium hydride for several days, distilled and kept over molecular sieve pellets (Linde, 4A). Cyclohexylamine was dried over potassium hydroxide. Triethylammonium bicarbonate solution was prepared by passing through carbon dioxide into $1 \mathrm{M}$ triethylamine until $\mathrm{pH}$ of the solution became 7.5.

Paper electrophoresis was carried out at $700 \mathrm{~V}(35 \mathrm{~cm})$ using Toyo No. 51 paper. The buffer used was $0.1 \mathrm{M}$ triethylammonium bicarbonate, $\mathrm{pH}$ 7.5. Electrophoretic mobilities of various compounds relative to that of uridine $2^{\prime}\left(3^{\prime}\right)$-phosphate are given in Tables 1 and 2 .

Table 1. Rf and Rm values of nucleotides and derivatives.

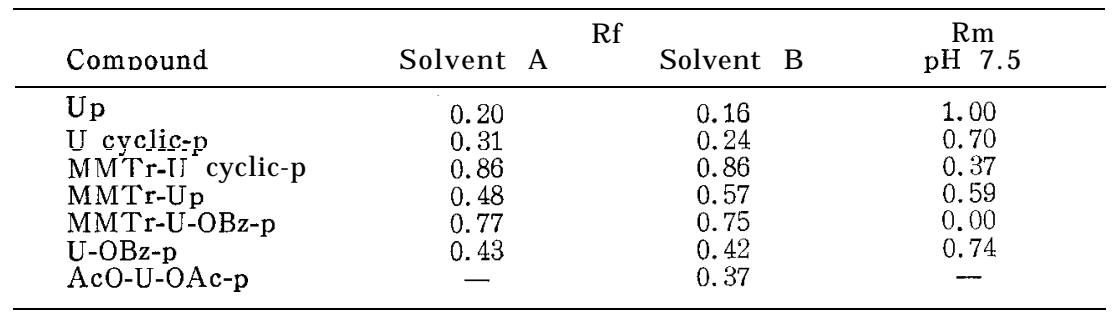

Table 2. Rf and $\mathrm{Rm}$ values of oligonucleotides.

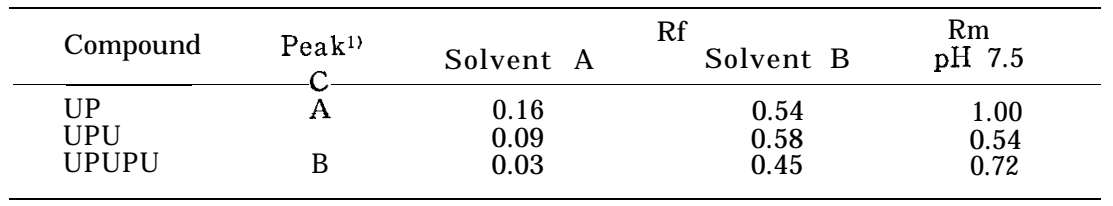

1) See Fig. 5.

Paper chromatography was performed using ascending technique with Toyo No. 51 paper. The solvent systems used were; solvent A, 2-propanol-concentrated ammonium hydroxide-water $(7: 1: 2 \mathrm{v} / \mathrm{v})$; solvent $\mathrm{B}$, ethanol-1 $\mathrm{M}$ ammonium acetate, $\mathrm{pH} 7.5(7: 3 \mathrm{v} / \mathrm{v})$; solvent $\mathrm{C}$, 1-butanol-acetic acid-water, (5: 2: $3 \mathrm{v} / \mathrm{v})$; solvent D, 1-propanol-concentrated ammonium hydroxide-water, (55:10:33 v/v). The Rf values of compounds were listed in Tables 1 and 2 .

The purity of the protected nucleosides was checked by thin layer chromatography on silica gel HF 254 using solvent E, methanol-benzene (1: $10 \mathrm{v} / \mathrm{v})$ and solvent F, methanol-chloroform (1: $10 \mathrm{v} / \mathrm{v})$.

Trityl- or monomethoxytrityl-containing compounds were made visible on paper or thin layer chromatograms by spraying with $10 \%$ perchloric acid and heating. Phosphorus-containing compounds were detected by molybdate-perchloric acid spray and UV irradiation. Sulfur-containing compounds were detected by palladium chloride spray. 
Degradations with pancreatic ribonuclease A were carried out by incubating a mixture of $0.25 \mu$ mole of a oligonucleotide, $10 \mu$ mole of Tris chloride buffer, pH 7.5 and $12.5 \mu \mathrm{g}$ of the enzyme in a total volume of $0.1 \mathrm{ml}$ at $37^{\circ} \mathrm{C}$ for $24 \mathrm{hr}$. The ratio of the products was estimated from optical density units of the water extracts of the appropriate spots on paper electrophorograms.

NMR spectrum was measured with a Hitachi Perkin Elmer R-20 High Resolution NMR Spectrometer $(60 \mathrm{MHz})$.

\section{$5^{\prime}$-O-Trityluridine}

The tritylation of uridine was carried out using trityl chloride in pyridine solution. Starting from $1 \mathrm{~g}$ of uridine, $2 \mathrm{~g}$ of $5^{\prime}$-0-trityluridine was obtained (98 \%). When the compound was contaminated with bis-trityluridine, it was recrystallized from acetone-ether. Thin layer chromatography (solvent E) showed that the compound was free of bis-trityluridine. M. p. 200-209 ${ }^{\circ} \mathrm{C}$. Anal. Calcd. for $\mathrm{C}_{28} \mathrm{H}_{26}$ (m. w. 486.5) : C, 69.11; H, 5.39; N, 5.76. Found: C, 68.95; H, 5.44; N, 5.82.

\section{$N, 2^{\prime}, 3^{\prime} \cdot O$-Tribenzoyluridine (X)}

To a solution of $5^{\prime}$-O-trityulridine ( $\left.500 \mathrm{mg}, 1.03 \mathrm{mmole}\right)$ in dry pyridine $(1.4$ $\mathrm{ml})$, freshly distilled benzoyl chloride $(0.6 \mathrm{ml}, 5.14 \mathrm{mmole})$ was added dropwise with stirring under ice-cooling. The mixture was left stand for $12 \mathrm{hr}$ at room temperature, and poured into ice-water $(100 \mathrm{ml})$ with vigorous stirring. The mixture was extracted with chloroform (three $20-\mathrm{ml}$ portions), and the extract was dried over sodium sulfate, and evaporated to dryness. The residue dissolved in a little amount of chloroform was applied to silica gel column $(1.5 \times 30 \mathrm{~cm})$ and eluted with chloroform. The eluate was evaporated to dryness and dissolved in $80 \%$ acetic acid $(20 \mathrm{ml})$. The solution was refluxed for $30 \mathrm{~min}$, and the solvent was removed by evaporation and then by coevaporation with toluene. The residue was dissolved in a small amount of absolute ethanol and poured into cyclohexane. The white precipitate was collected by filtration and dried over phosphorus pentoxide in vacuo. The yield was $408 \mathrm{mg}$ (81 \%). It was recrystallized from ethanol. Thin layer chromatography using solvent $\mathrm{E}$ showed that the compound was pure. M. p. $192-193^{\circ} \mathrm{C}$. Anal. Calcd. for $\mathrm{C}_{30} \mathrm{H}_{24} \mathrm{O}_{9} \mathrm{~N}_{2}(\mathrm{~m}$. w. 556.5) : C, 64,74; H, 4.35; N, 5.03 Found: C, 64.68; H, 4.43; N, 4.92.

\section{2',5'-O-Diacetyluridine $3^{\prime}$-phosphate (X II)}

Acetylation of two hydroxy functions of uridine $3^{\prime}$-phosphate was carried out in tetraethylammonium acetate buffer using acetic anhydride as acylating agent under strictly anhydrous condition. Starting from $160.9 \mathrm{mg}$ of pyridinium uridine $3^{\prime}$-phosphate ( 2 mmole), the desired product was obtained in pyridinium form quantitatively $(1.157 \mathrm{~g})$.

\section{$5^{\prime}$-O-Monomethoxytrityluridine (VZ)}

A mixture of uridine (1.22 g, 5 mmole) and monomethoxytrityl chloride (2.10 $\mathrm{g}, 6.5 \mathrm{mmole}$ ) was dissolved in dry pyridine $(25 \mathrm{ml})$ and left stand for $48 \mathrm{hr}$ at room temperature. The mixture was evaporated in vacuo and dissolved in ethyl acetate $(50 \mathrm{ml})$. The organic layer was washed with water (two $40-\mathrm{ml}$ portions), and dried over sodium sulfate. The solution was evaporated to dryness, dissolved in a small amount of benzene, and kept for several hours at room temperature. The white crystals were collected by filtration, washed with benzene, 
and dried over phosphorus pentoxide in vacuo. The yield was $3.45 \mathrm{~g}$ (quantitative). The purity of the compound was checked by thin layer chromatography on silica gel HF 254 with solvent F. Anal. Calcd. for $\mathrm{C}_{29} \mathrm{H}_{28} \mathrm{O}_{7} \mathrm{~N}_{2} \cdot 1.5 \mathrm{C}_{6} \mathrm{H}_{6}(\mathrm{~m}$. w. 633) ; C, 71.86; H, 5.85; N, 4.40. Found: C, 72.02; H, 5.88; N, 4.42.

\section{$5^{\prime}$-O-Monomethoxytrityluridine $2^{\prime}, 3^{\prime}$-cyclic phosphate (VZZ)}

A mixture of 5'-0-monomethoxytrityluridine (1.655 g, $3 \mathrm{mmole}$ ) and MTBO (0.778 g, 3.6 mmole) was dissolved in dry dimethylformamide and cooled with liquid nitrogen. Cyclohexylamine $(3.6 \mathrm{ml}, 30 \mathrm{mmele})$ was added to the solution and shaken for $4 \mathrm{hr}$ at $70^{\circ} \mathrm{C}$. The spectrophotometrical yield was $80 \%$. The mixture dissolved in 50 \% aqueous methanol $(50 \mathrm{ml})$ was applied to a column $(3.2 \times 50$ $\mathrm{cm}$ ) of DEAE-cellulose (bicarbonate form), washed with the same solvent (1 1 ) and then with water $(41)$. The elution was carried out with $0.025 \mathrm{M}$ triethylammonium bicarbonate (5 1). The eluate was condensed under reduced pressure and removed the solvent by coevaporation with water. The residue dissolved in water was slowly passed through a Dowex-50W (sodium) column $(2 \times 20$ $\mathrm{cm})$. The column was washed with water $(500 \mathrm{ml})$. The eluate was condensed and made anhydrous by coevaporation with absolute ethanol. The residue dissolved in a small amount of methanol was poured into an excess of ether with vigorous stirring. The white precipitate was collected by centrifugation and dried over phosphorus pentoxide in vacuo. Anal. Calcd. for $\mathrm{C}_{29} \mathrm{H}_{26} \mathrm{O}_{9} \mathrm{~N}_{2} \mathrm{P} \cdot \mathrm{Na}$. 1.5 $\mathrm{H}_{2} \mathrm{O}$ (m. w. 601.5) : C, 55.4: H, 4.65; N, 4.46. Found: C, 55.20; H, 4.67; N, 4.66.

\section{5'-O-Monomethoxytrityl-2'-O-benzoyluridine $3^{\prime}$-phosphate (VZZZ)}

To a solution of sodium $5^{\prime}$-O-monomethoxytrityluridine $2^{\prime}, 3^{\prime}$-cyclic phosphate (1.314 g, 2 mmole) in $60 \mathrm{ml}$ of $0.05 \mathrm{M}$ triethylammonium bicarbonate buffer ( $\mathrm{pH}$ 7.5), bovine pancreatic ribonuclease A ( $2 \mathrm{mg}$ ) was added, and the solution was stirred for $48 \mathrm{hr}$ at $37^{\circ} \mathrm{C}$. The completion of the reaction was confirmed by paper electrophoresis. After the starting material was completely disappeared, the reaciton mixture was passed through a column $(1.2 \times 2.0 \mathrm{~cm})$ of Dowex-50W (triethylammonium). The column was washed with water and the eluate was evaporated under reduced pressure, rendered anhydrous by repeated evaporation with pyridine. Finally pyridine was removed by coevaporation with toluene. To the residue was added benzoic anhydride $(40 \mathrm{mmole})$ and the mixture was heated at $50^{\circ} \mathrm{C}$ under stirring until the olid material was dissolved and kept for 2 days at $30^{\circ} \mathrm{C}$. Aqueous pyridine $(50 \%, 30 \mathrm{ml})$ was added to the mixture under ice-cooling. The solution was washed with pentane (two 30-ml portions) and extracted with chloroform. The chloroform layer was evaporated in vacuo. The residue was made anhydrous by coevaporation with pyridine. The pyridine solution was dropped into a mixture of ether-pentane $(3: 2)$ under stirring. The white precipitate was collected by centrifugation and treated with acetic anhydride $(10 \mathrm{ml})$ in pyridine $(20 \mathrm{ml})$ for $24 \mathrm{hr}$ at $30^{\circ} \mathrm{C}$. Aqueous pyridine $(50 \%, 30 \mathrm{ml})$ was added to the solution under ice-cooling. The solution was passed through a column $(1.0 \times 2.0$ $\mathrm{cm}$ ) of Dowex-SOW (pyridinium). The total effluent and washings (with $25 \%$ aqueous pyridine) were kept for $2 \mathrm{hr}$ at room temperature and evaporated with pyridine. The anhydrous residue in a small amount of pyridine was dropped into large excess of a mixture of ether-pentane (3: 2). The white precipitate was collected by centrifugation and dried over phosphorus pentoxide in vacuo. The 
yield was $1.003 \mathrm{~g}(66 \%)$. Anal. Calcd. for $\mathrm{C}_{36} \mathrm{H}_{31} \mathrm{O}_{11} \mathrm{~N}_{2} \mathrm{P} \cdot 2 \mathrm{C}_{5} \mathrm{H}_{5} \mathrm{~N} \cdot 1.5 \mathrm{H}_{2} \mathrm{O}$ (m. w. 885.8) : C, 62.50; H, 5.02; N, 6.34. Fond: C, 62.68: H, 5.36; H, 5.36; N, 6.35.

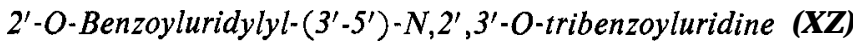

$5^{\prime}$-O-Monomethoxytrityl-2'-O-benzoyluridine $3^{\prime}$-phosphate (516 mg, $0.6 \mathrm{mmole}$ ) and $\mathrm{N}, 2^{\prime}, 3^{\prime}-\mathrm{O}$-tribenzoyluridine $(668 \mathrm{mg}, 1.2 \mathrm{mmole})$ were condensed to the dinucleotide with dicyclohexylcarbodiimide in pyridine (Lohrmann et al., 1966). Then monomethoxytrityl group of the resulting dinucleotide was removed by acetic acid. After successive routine procedure, the desired product was obtained. The yield was $300 \mathrm{mg}(96 \%)$. Anal. Calcd. for $\mathrm{C}_{46} \mathrm{H}_{38} \mathrm{O}_{18} \mathrm{~N}_{4} \mathrm{PC}_{5} \mathrm{H}_{5} \mathrm{~N} \cdot 2.5 \mathrm{H}_{2} \mathrm{O}$ (m. w. 1,090): C, 56.20; H, 4.58; N, 6.42. Found: C, 56.62: H, 4.54; N, 6.36.

\section{Uridylyl- $\left(3^{\prime}-5^{\prime}\right)$-uridylyl-(3'-5')-uridine (XIII)}

The trinucleotide was synthesized from $2^{\prime}$-O-benzolyluridylyl- $\left(3^{\prime}-5^{\prime}\right)-\mathrm{N}, 2^{\prime}, 3^{\prime}-$ 0 -tribenzoyluridine $(109.0 \mathrm{mg}, 0.1 \mathrm{mmole})$ and $2^{\prime}, 5^{\prime}$-O-diacetyluridine $3^{\prime}$-phosphate (169.2 $\mathrm{mg}, 0.3 \mathrm{mmole}$ ) by the aid of dicyclohexylcarbodiimide in dry pyridine (Lohrmann et al., 1966). Removal of the blocking groups of the resulting trinucleotide was accomplished with $15 \mathrm{~N}$ methanolic ammonia. DEAE-cellulose column chromatography separated the desired trinucleotide from the starting dinucleotide and nucleoside. The deblocked trinucleotide was obtained as sodium salt (8.2 mg. $34 \%)$.

\section{RESULTS AND DISCUSSION}

\section{Reaction of MTBO with nucleosides}

MTBO reacts with ribonucleosides in the presence of cyclohexylamine to give ribonucleoside $2^{\prime}, 3^{\prime}$-cyclic phosphates (V) and $5^{\prime}$-S-methylphosphorothiolate (II). Both are key intermediate in the synthesis of oligonucleotides and nucleoside $3^{\prime}, 5^{\prime}$-cyclic phosphates such as so-called cyclic AMP (Eto et al., 1974). The $2^{\prime}, 3^{\prime}$-cyclic phosphates might be produced by intramolecular attack of the adjacent hydroxy group to phosphorus atom of the intermediate $2^{\prime}\left(3^{\prime}\right)$-S-methyl phosphorothiolate (IV) (Eto et al., 1971). When $5^{\prime}$-hydroxy group was blocked to avoid the formation of $5^{\prime}$-phosphorothiolate, $2^{\prime}, 3^{\prime}$-cyclic phosphate was produced in a good yield. We employed monomethoxytrityl [MMTr-, $p-\mathrm{CH}_{3} \mathrm{O}-\mathrm{C}_{6} \mathrm{H}_{5} \mathrm{C}$ $\left(\mathrm{C}_{6} \mathrm{H}_{5}\right)_{2}-3$ group as a protector (Fig. 3). It blocked the $5^{\prime}$-hydroxy function appropriately both in MTBO reaction and in phosphorylation using dicyclohexylcarbodiimide to synthesize dinucleotide, UpU. Moreover it can be selectively removed from the fully blocked dinucleotide without affecting other protectors such as benzoyl groups. The regenerated $5^{\prime}$-hydroxy group can react with $3^{\prime}$-phosphate group of another nucleotide to give the desired trinucleotide, UpUpU.

We obtained 5'-O-monomethoxytrityluridine $3^{\prime}$-phosphate (VIII) via 2', 3'-cyclic phosphate (VII). The latter was produced in a good yield $(80 \%)$ in the reaction of MTBO and 5'-O-monomethoxytrityluridine (VI) with cyclohexylamine. Identification of the desired cyclic phosphate (VII) was carried out by paper chromatography, electrophoresis and enzymatic hydrolysis in combination with absorption measurement besides elemental analysis. NMR spectrum of triethylammonium salt of the cyclic phosphate (VII) in heavy chloroform gave little information about the site of phosphate ester linkage due to large contribution of 


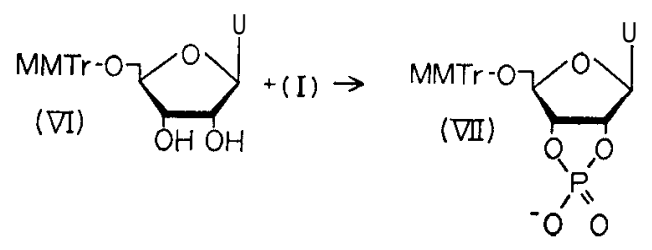

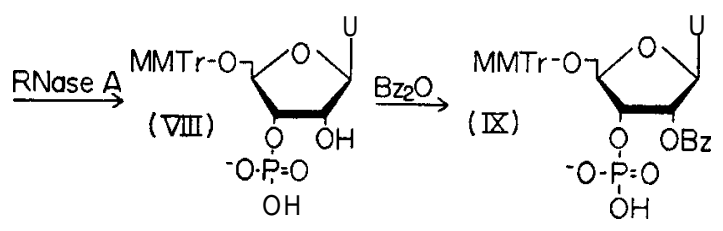

Fig. 3. Preparation of $2^{\prime}, 5^{\prime}$-protected uridine $3^{\prime}$-phosphate.

bulky monomethoxytrityl and triethyl groups to the molecular weight, which caused overlapping of signals.

Paper electrophoresis of the MTBO reaction mixtue showed that one of the by-products migrated faster than $2^{\prime}$, Y-cyclic phosphate (VII) toward the anode and gave a positive test with palladium reagent indicating the existence of methylthio group. Molybdate test showed the existence of phosphorus atom. Its UV absorption was identical with that of the starting Y-O-protected nucleoside (VI). The starting nucleoside (VI) has hydroxyl groups only at 2' and 3' position that can be phosphorylated by MTBO. These results indicated that the by-product would be $5^{\prime}$-O-monomethoxytrityluridine $2^{\prime}, 3^{\prime}$-bis (S-methyl phosphorothiolate). The desired nucleotide was separated from the by-product and starting material by DEAE-cellulose column chromatography.

\section{Synthesis of the trinucleotide}

Condensing the protected uridine $3^{\prime}$-phosphate (IX) with the protected nucleoside bearing a free $5^{\prime}$-hydroxy group provides the most satisfactory results for the specific synthesis of the $\mathrm{C}_{3} \cdot \mathrm{C}_{5}$. internucleotidic linkage. $\mathrm{N}, 2^{\prime}, 3^{\prime}$-O-tribenzoyluridine (X) and $5^{\prime}$-O-monomethoxytrityl-2'-O-benzoyluridine $3^{\prime}$-phosphate (IX)

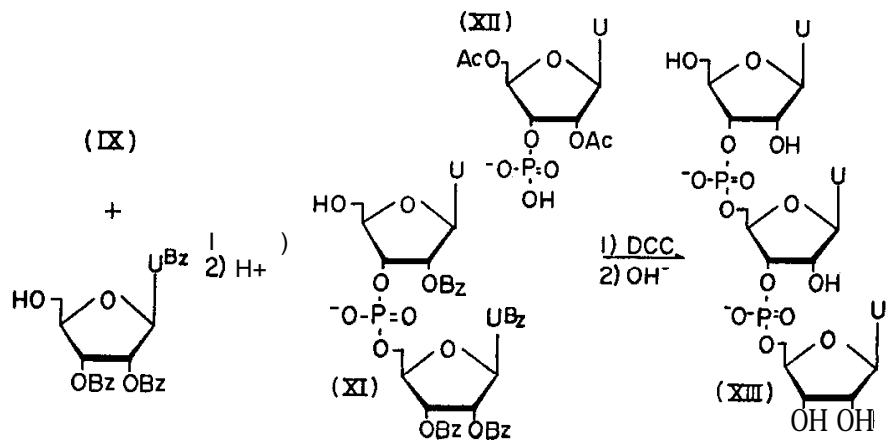

Fig. 4. Synthetic steps of UpUpU. 
were condensed with dicyclohexylcarbodiimide followed by acid treatment to give a dinucleoside monophosphate (XI) bearing a free $5^{\prime}$-hydroxy group. $2^{\prime}$-O-Benzoyluridylyl- $\left(3^{\prime}-5^{\prime}\right)-\mathrm{N}, 2^{\prime}, 3^{\prime}-\mathrm{O}$-tribenzoyluridine (XI) extracted from the reaction mixture was used as an intermediate for the next synthetic step of UpUpU (XIII) without purification by ion exchange chromatography. The preparation method of XIII is shown in Figs. 3 and 4. $5^{\prime}$-O-Protected uridine $2^{\prime}, 3^{\prime}$-cyclic phosphate prepared by MTBO method was converted to the corresponding $3^{\prime}$-phosphate (VIII) with pancreatic ribonuclease A, and then to IX with benzoic anhydride. As $5^{\prime}$ terminal nucleotide, $2^{\prime}, 5^{\prime}$-O-diacetyluridine $3^{\prime}$-phosphate (XII) was used. UpUpU (XIII) was prepared by the same procedure as used in the preparation of XI. The product XIII was isolated by DEAE-cellulose column chromatography, after removal of protecting acyl groups. The elution pattern is shown in Fig. 5. The peak A compound was identified as the starting dinucleotide (XI), the peak B

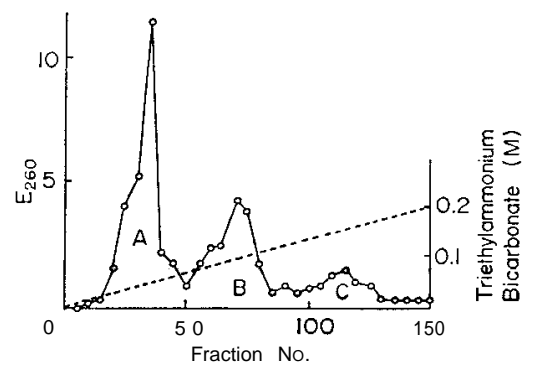

Fig. 5. DEAE-cellulose column chromatogram of the condensation products of Up and UpU.

as the desired trinucleotide (XIII) and the peak $\mathrm{C}$ as the starting mononucleotide by paper chromatography and paper electrophoresis. The trinucleotide (XIII) was also characterized by hydrolysis with ribonuclease A to give mononucleotide and nucleoside in the theoretical ratio (Table 3 ).

Table 3. Characterization of oligonucleotides by enzymatic degradation.

\begin{tabular}{|c|c|c|c|c|c|}
\hline Compound & Peak $^{1)}$ & $\underset{\text { enzymatic }}{\mathrm{E}_{260} \mathrm{u}}$ & $\begin{array}{l}\text { its after } \\
\text { degradation } \\
\mathbf{U}\end{array}$ & $\begin{array}{l}\mathrm{Up} / \mathrm{U} \\
\text { Calcd. }\end{array}$ & $\begin{array}{l}\text { Ratio } \\
\text { Found }\end{array}$ \\
\hline $\begin{array}{l}\mathrm{U} p U \mathrm{pU} \\
\mathrm{U}\end{array}$ & $\begin{array}{l}\mathrm{A} \\
\mathrm{B}\end{array}$ & $\begin{array}{l}0.875 \\
\text { 2. a25 }\end{array}$ & $\begin{array}{l}0.830 \\
1.370\end{array}$ & $\frac{1}{2}$ & $\begin{array}{l}1.05 \\
\mathbf{2 . 0 6}\end{array}$ \\
\hline
\end{tabular}

1) See Fig. 5.

The present method could be applied to the synthesis of various oligonucelotides starting from nucleosides, enabling the synthesis of oligonucleotides of different conformation from natural one and containing minor, rare or artificial bases. 


\section{REFERENCES}

Eto, M., hf. Sasaki, M. Iio, My. Eto and H. Okawa 1971 Synthesis of 2-methylthio-4H-1,3,2benzodioxaphosphorin-Z-oxide by thiono-thiol conversion and its use as phosphorylating agent. Tetrahedron Letters, 45: 4263-4266

Eto, My., M. Iio, Y. Kobayashi, H. Omura and M. Eto 1974 Synthesis of ribonucleoside-5'S-methyl phosphorothiolates and ribonucleoside- $3^{\prime}, 5^{\prime}$-cyclic phosphates from nucleosides applying a new phosphorylating agent, MTBO. Agr. Biol. Chem., 38: 2081-2092.

Iio, M., My. Eto, M. Eto and H. Omura 1973 Reaction of MTBO with alcohols. Agr. Biol. Chem., 37: 115-121

Lohrmann, R., D. Sö11, H. Hayatsu, E. Otsuka and H. G. Khorana 1966 Studies on polynucleotides. LI. Syntheses of the 64 possible ribonucleotides derived from the four major ribonucleotides. J. Am. Chem. Soc., 88: 819-829

Murakami, H, and K. Yamafuji 1970 Mode of action of some catecholamines and sugar oximes on deoxyribonucleic acid. Enzymologia, 38: 337-345

Yamafuji, K., M. Iio and My. Eto 1970 Interaction of deoxyribonucleic acid with xylans having antitumor activity. Z. Krebsforsch., 75: 55-58

Yamafuji, K., K. Shinohara, F. Yoshihara, M. Iio and Y. Torikai 1971 Breakage of nucleic acids as initiative process of cytodifferentiation and cytoanomalization. Enzymologia, 40 : $107-119$ 